\title{
Endoscopic ultrasound-guided transmural drainage by cautery- tipped lumen-apposing metal stent: exploring the possible indications
}

\author{
Andrea Anderlonia, Milena Di Leo ${ }^{a, b}$, Silvia Carrara ${ }^{a}$, Alessandro Fugazza ${ }^{a}$, Roberta Masellia, \\ Andrea Budac, Arnaldo Amato d, Francesco Auriemma ${ }^{a}$, Alessandro Repicia,b
}

Humanitas Research Hospital, Milan; Humanitas University, Rozzano, Milan; Digestive Endoscopy Unit, Feltre, Gastroenterology Division, Valduce, Como, Italy

\section{Abstract}

\begin{abstract}
Background The recently introduced Hot $\mathrm{AXIOS}^{\mathrm{m}}$ system for endoscopic ultrasound (EUS)guided transenteric drainage has the potential to change interventional endoscopy significantly. The aim of our study was to assess the effectiveness and safety of this new type of lumen-apposing metal stent (LAMS) with cautery system for pancreatic collection, and gallbladder and biliary tree drainage.
\end{abstract}

Methods We retrospectively reviewed consecutive patients undergoing EUS-guided drainage by LAMS with cautery system in a tertiary-care academic medical center between March 2014 and March 2017. All patients were included in our prospectively maintained institutional EUS database. The main outcome measures were technical success, clinical effectiveness, and adverse events.

Results A total of 45 patients (20 men, mean age 69.6 years) underwent LAMS placement. Indications were pancreatic fluid collections (19 patients, $42.2 \%$ ), acute cholecystitis (10 patients, $22.2 \%$ ), and biliary drainage (16 patients, $35.5 \%)$. Technical success was achieved in all patients except one (97.7\%). Clinical success was achieved in $86.4 \%(38 / 44)$ of cases and adverse events occurred in $5(11.4 \%)$ of patients.

Conclusions In our experience, EUS-guided LAMS placement performed by expert endoscopists was feasible and effective in the endoscopic management of pancreatic fluid collection, and biliary and gallbladder drainage. Optimization of transmural drainage by new dedicated devices could improve efficacy and safety in appropriately selected patients.

Keywords Pancreatic fluid collection drainage, gallbladder drainage, biliary drainage, lumen apposing metal stent, Hot AXIOS stent

Ann Gastroenterol 2018; 31(6): 1-7

\begin{abstract}
${ }^{\text {a }}$ Digestive Endoscopy Unit, Department of Gastroenterology, Humanitas Research Hospital, Milan (Andrea Anderloni, Milena Di Leo, Silvia Carrara, Alessandro Fugazza, Roberta Maselli, Francesco Auriemma, Alessandro Repici); 'Humanitas University, Rozzano, Milan (Milena Di Leo, Alessandro Repici); ${ }^{\mathrm{c} D i g e s t i v e ~ E n d o s c o p y ~ U n i t, ~ F e l t r e ~}$ (Andrea Buda); ${ }^{\mathrm{d}}$ Gastroenterology Division, Valduce, Como (Arnaldo Amato), Italy

Conflict of Interest: None
\end{abstract}

Correspondence to: Andrea Anderloni, MD, PhD, Digestive Endoscopy Unit, Department of Gastroenterology, Humanitas Research Hospital, 56 Via Manzoni, 20089 Rozzano, Milan, Italy,

e-mail: andrea.anderloni@humanitas.it

Received 28 April 2018; accepted 25 June 2018; published online 26 July 2018

DOI: https://doi.org/10.20524/aog.2018.0299

\section{Introduction}

Interventional endoscopic ultrasonography (EUS) is a wellestablished procedure for transenteric drainage. This technique has emerged recently as an interesting and useful modality for achieving drainage of pancreatic fluid collections (PFCs) [1], and of the gallbladder [2,3] and biliary tract [4]. In this setting, new devices specifically designed for interventional EUS, such as Hot AXIOS $^{\text {тx }}$ (Boston Scientific Corp., Marlborough, MA, United States), have significantly changed the technical approach, allowing a simple, safe and time-saving procedure, as recently shown in a number of cohort studies [5,6]. The Hot $\mathrm{AXIOS}^{\mathrm{mm}}$ stent is a novel, fully covered, self-expanding, lumenapposing metal stent (LAMS) mounted on an electrocautery- 
enhanced delivery system designed for minimally invasive transgastric or transduodenal EUS-guided drainage.

The aim of this study was to evaluate the feasibility, safety and efficacy of LAMS placement in consecutive patients referred to our tertiary center for transmural drainage of PFCs, and of the gallbladder and biliary tree.

\section{Patients and methods}

We retrospectively reviewed consecutive patients who underwent EUS-guided drainage by LAMS in our tertiarycare academic referral center between March 2014 and March 2017. Written informed consent was obtained from all patients. The study was performed in accordance with the Helsinki Declaration. The retrospective analysis of the data was approved by our Institutional Review Board.

All endoscopic procedures were performed according to the European Society of Gastrointestinal Endoscopy's practice guidelines on antibiotic prophylaxis and the management of antithrombotic agents and coagulopathy [7]. Patient demographics, clinical indications, and pre- and post-procedural data were collected. The clinical indications included PFCs, gallbladder and biliary drainage. According to the guidelines $[8,9]$, EUS drainage of PFCs was performed when patients became symptomatic because of size increase or in the event of infection.

EUS-guided biliary drainage was performed in patients with unresectable pancreatic or biliary cancer who had undergone a failed attempt at biliary drainage by endoscopic retrograde cholangiopancreatography (ERCP) [4]. Gallbladder drainage was performed in high-risk surgical patients with a diagnosis of acute cholecystitis, based on the Tokyo Guidelines as a combination of clinical symptoms, laboratory tests and radiological findings $[2,10,11]$.

\section{Technique for EUS-guided transmural drainage}

The new LAMS (Hot AXIOS ${ }^{\mathrm{rm}}$, Boston Scientific Corp., Marlborough, MA, United States) is a fully covered selfexpanding stent preloaded with the Hot AXIOS ${ }^{\mathrm{Tm}}$ Delivery System, a through-the-scope electrocautery-enhanced delivery system compatible with therapeutic echoendoscopes having a working channel of $3.7 \mathrm{~mm}$ diameter or larger. The delivery system allows endoscopic control and employs a locked twostep release system to prevent unintended deployment of the proximal flange. The stent has bilateral anchor flanges to provide lumen-to-lumen anchoring. These features reduce the risk of stent migration and leakage alongside the stent, as well as preventing tissue in-growth and enabling easy removal.

The EUS procedures were performed by two experienced endosonographers (A.A., S.C. with more than 500 ERCP/ EUS per year). Linear array Olympus GF-UCT-180 series echoendoscopes at 5-10 MHz (Olympus Europe, SE \& CO, $\mathrm{KG}$, Hamburg, Germany) were used in combination with the echoprocessor EU-ME2 (Olympus Europe, SE \& CO, KG, Hamburg, Germany). Luminal insufflation was performed using carbon dioxide. The procedures were performed on an inpatient basis under deep sedation or under general anesthesia at the discretion of anesthesiologist.

All patients were given intravenous antibiotics preoperatively and antibiotic therapy was maintained for at least 6 days after stent placement. Under EUS guidance, the relevant target was imaged and punctured from either the stomach or duodenum using the energized device operated under the pure-cut setting (Autocut mode, effect 5; ERBE Electrosurgery, Tübingen, Germany). Following EUS confirmation of the correct position of the device inside the target lesion, the distal end of the stent was deployed according to the intra-channel release technique [12]. All patients were followed up daily until discharge, after which they were followed up according to the indication for LAMS placement.

Patients treated for PFCs were evaluated with contrastenhanced computed tomography (CT) imaging after 2 months, and stent removal was scheduled upon resolution of the collection. Patients who underwent biliary and gallbladder drainage were evaluated 30 days after discharge and every three months for a total follow-up of one year. LAMS removal was scheduled after 3 months, when indicated.

\section{Outcome measures}

Technical success was defined as correct LAMS placement. Clinical success was defined according to the different clinical indications: complete resolution of the PFCs and of the patient's symptoms in PFC drainage; radiologic evidence of gallbladder decompression and resolution of clinical symptoms in cholecystitis; serum bilirubin level decrease of $50 \%$ or more within 2 weeks following the procedure of biliary drainage for unresectable bile duct and pancreatic cancer. Adverse events were classified either as intraprocedural, or as immediate or late, according to whether adverse events occurred less or more than $24 \mathrm{~h}$ after stent placement, respectively [13]. Technical success of LAMS removal was defined as successful removal during upper endoscopy of the LAMS, using a polypectomy snare or rat-tooth forceps in a single session.

\section{Statistical analysis}

SPSS (version 17.0) statistical software was used for the data analysis. Continuous variables were reported using mean \pm standard deviation (SD) and range. Categorical variables were reported in terms of frequency counts and proportions.

\section{Results}

A total of 45 patients (20 men, mean age $69.6 \pm 14.2$ [range 37-90] years) were treated with LAMS placement. The indications for EUS drainage were PFCs in 19 patients (42.2\%), 
acute cholecystitis in 10 (22.2\%), and distal biliary obstruction in $16(35.5 \%)$. The mean duration of the entire procedure was $26.5 \pm 17.4$ (range 7-97) $\mathrm{min}$ and the mean time required for stent placement was $3.1 \pm 2.2$ (range 1-15) $\mathrm{min}$. The stent access route was through the duodenum in $22(48.9 \%)$ patients and the stomach in 23 (51.1\%).

Technical success was achieved in all but one patient (98.0\%). The unsuccessful case was a patient with biliary obstruction due to pancreatic cancer. After LAMS stent placement, misdeployment of the stent was observed.

Clinical success was achieved in $86.4 \%$ (38/44) of cases and adverse events occurred in $5(11.4 \%)$ patients: 1 self-limited intraprocedural bleeding during gallbladder drainage, 2 late reinfections of necrotic pancreatic collection, 1 perforation, and 1 fatal adverse event due to severe acute arterial bleeding after biliary drainage.

\section{PFC drainage}

We evaluated 19 patients with PFCs treated with LAMS (Fig. 1). The patient characteristics and endoscopic treatments performed are shown in Table 1. The type of collection was pseudocysts in $16(84.2 \%)$ patients and walled-off necrosis (WON) in $3(15.8 \%)$. The mean size of the collection, as measured by EUS, was $10.2 \pm 3.5 \mathrm{~cm}$. The mean time required for stent positioning was $2.6 \pm 1.57 \mathrm{~min}$. Technical success was achieved in all cases. No adverse events occurred during the procedures or within $24 \mathrm{~h}$ after stent placement.

One patient died two days after stent placement from renal failure related to severe acute biliary pancreatitis. The remaining 18 patients were followed up for a mean of $426.5 \pm 234.8$ (range 68-804) days. Regarding clinical effectiveness, complete resolution of PFCs was observed in 15 (83.3\%) patients. The other 3 patients had a partial resolution of PFC (more than $50 \%$ in size) with complete resolution of symptoms. Stent removal was performed in 17/18 patients, without any adverse events. All stents were removed during a fluoroless procedure using a polypectomy snare.

Adverse events occurred in $2(11.1 \%)$ patients and included new-onset infection related to stent dysfunction and migration. In the first patient, stent occlusion by necrotic debris 28 days after the procedure led to infection of the PFC. The patient was successfully treated with antibiotics, followed by endoscopic
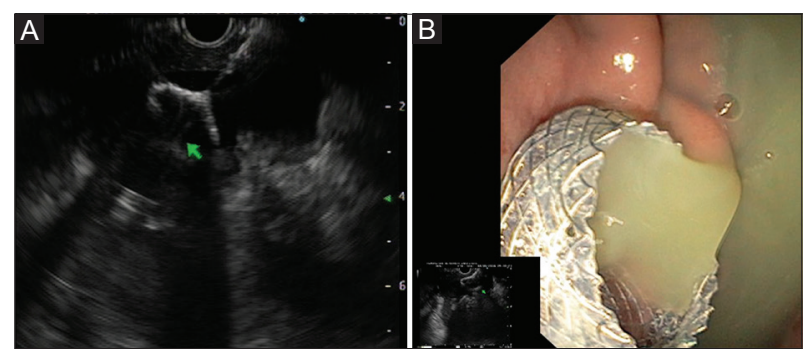

Figure 1 (A) Endoscopic ultrasound-guided drainage of walled-off necrosis by positioning a lumen-apposing metal stent (LAMS). (B) Endoscopic view of the proximal flange of the LAMS placed across the gastric corpus necrosectomy in combination with nasocystic drainage. A CT scan performed two months after necrosectomy revealed complete resolution of WON and stent migration.

In the second patient, infection occurred 31 days after the procedure as a result of stent migration in the duodenal cavity. The patient was successfully treated with antibiotics and endoscopic necrosectomy in combination with nasocystic drainage performed through the fistula previously created by the LAMS. A CT scan performed after two months revealed complete resolution of WON, and the patient was asymptomatic during follow up.

Table 1 Patients who underwent endoscopic ultrasound-guided pancreatic collection drainage with a lumen-apposing metal stent

Characteristics of patients $(\mathrm{N}=19)$

\begin{tabular}{|c|c|}
\hline $\operatorname{Sex}[\mathrm{n}(\%)]$ & Male $7(36.8 \%)$ \\
\hline Age, y $[$ mean \pm SD] & $64.3 \pm 14.6$ \\
\hline \multirow{4}{*}{$\begin{array}{l}\text { Etiology of pancreatic } \\
\text { collection }[\mathrm{n}(\%)]\end{array}$} & Alcohol pancreatitis $2(10.5 \%)$ \\
\hline & Gallstone pancreatitis $10(52.6 \%)$ \\
\hline & Idiopathic pancreatitis 5 (26.4\%) \\
\hline & Postsurgical $2(10.5 \%)$ \\
\hline \multirow{4}{*}{$\begin{array}{l}\text { Indication for } \\
\text { drainage [n (\%)] }\end{array}$} & Infection 5 (26.4\%) \\
\hline & $\begin{array}{l}\text { Compression (bile duct/ } \\
\text { stomach/vein) } 10(52.6 \%)\end{array}$ \\
\hline & Pain $2(10.5 \%)$ \\
\hline & Other $2(10.5 \%)$ \\
\hline \multirow{2}{*}{$\begin{array}{l}\text { Type of pancreatic } \\
\text { collection }[\mathrm{n}(\%)]\end{array}$} & Pseudocyst 16 (84.2\%) \\
\hline & $\begin{array}{l}\text { Walled-off pancreatic necrosis } \\
3(15.8 \%)\end{array}$ \\
\hline Diameter, $\mathrm{cm}[$ mean $\pm \mathrm{SD}]$ & $10.2 \pm 3.5$ \\
\hline Bulging [n (\%)] & $10(52.6 \%)$ \\
\hline Technical success [n (\%)] & $19(100 \%)$ \\
\hline $\begin{array}{l}\text { Procedural time, } \\
\text { min [mean } \pm S D]\end{array}$ & $13.9 \pm 4.28$ \\
\hline \multirow[t]{2}{*}{ Access route $[\mathrm{n}(\%)]$} & Transgastric 17 (89.5\%) \\
\hline & Transduodenal $2(10.5 \%)$ \\
\hline \multirow[t]{2}{*}{ Stent diameter $[\mathrm{n}(\%)]$} & $10 \mathrm{~mm} 4(21.1 \%)$ \\
\hline & $15 \mathrm{~mm} 15(78.9 \%)$ \\
\hline $\begin{array}{l}\text { Immediate adverse } \\
\text { events [n (\%)] }\end{array}$ & 0 \\
\hline $\begin{array}{l}\text { Late adverse } \\
\text { events }[\mathrm{n}(\%)]^{*}\end{array}$ & $2(11.1 \%)$ \\
\hline Clinical success $[\mathrm{n}(\%)]^{*}$ & $15(83.3 \%)$ \\
\hline $\begin{array}{l}\text { Follow-up duration } \\
\text { after stent insertion, } \\
\text { days [mean } \pm \text { SD] }\end{array}$ & $426.5 \pm 234.8$ \\
\hline
\end{tabular}




\section{Gallbladder drainage}

Ten patients with acute cholecystitis not fit for surgery were drained by LAMS placement (Fig. 2). The patient characteristics and endoscopic treatments performed are shown in Table 2. Three patients underwent gallbladder drainage outside the endoscopic room because the procedures were performed in the Intensive Care Unit.

The approach for EUS drainage was made through the duodenal bulb in 6 cases (60\%). Technical success was achieved in $100 \%$ of cases. The mean time required for stent positioning was $3.5 \pm 4.1 \mathrm{~min}$. Resolution of cholecystitis was observed in 9 of 10 patients (90\%). One patient died 3 days later from multiple organ failure. One incidence of self-limited intraprocedural bleeding was observed during gallbladder drainage and a naso-gallbladder drain was positioned. We observed one gallbladder perforation after 17 days, treated with surgery (the patient died after 63 days from multiple organ failure).

The mean follow up was $154.1 \pm 134$ days. None of these patients underwent stent removal. Although gallbladder drainage is generally intended as a bridge to elective surgery, none of the patients in our study turned out to be eligible for elective cholecystectomy, because of their high surgical risk.

\section{Biliary drainage}

Sixteen patients with obstructive jaundice due to unresectable pancreatic or biliary cancer and failed endoscopic transpapillary biliary drainage underwent biliary decompression by LAMS (Fig. 3). The patient characteristics and endoscopic treatments performed are shown in Table 3. The mean time required for stent positioning was $3.6 \pm 1.4 \mathrm{~min}$. Technical success was achieved in 15 cases. In the remaining patient, a misdeployment of the stent was observed: the distal flange was released in the space between the duodenal wall and the common bile duct wall. Therefore, the stent was removed endoscopically and the patient was immediately treated by ERCP after EUS-guided biliary rendezvous, with successful biliary cannulation and biliary stent placement.

In 5 patients $(31.3 \%)$, duodenal stenting for duodenal obstruction was performed during the same endoscopic procedure, with $100 \%$ technical success. There were no intraprocedural adverse events, as described in a previous study [14]. Clinical success was observed in 14 (93.3\%) of 15 patients.

During the follow-up period ( $138.7 \pm 124.6$ days), 1 (6.6\%) patient died from severe acute duodenal arterial bleeding, 24 days after stent placement. For the remaining patients no immediate or late adverse events were reported, though 8 patients died due to disease-related complications.

\section{Discussion}

In the last decade, endoscopic transluminal drainage has become the procedure of choice for pancreatic collections,
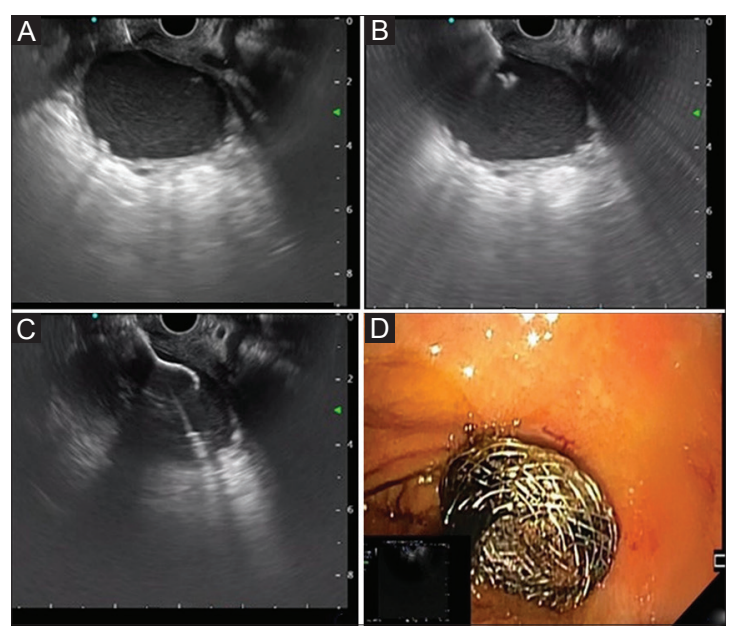

Figure 2 (A) Endoscopic ultrasound (EUS) view of acute cholecystitis. (B) EUS image of gallbladder punctured by cautery tip of the lumenapposing metal stent (LAMS). (C) EUS-guided gallbladder drainage by positioning a LAMS. (D) Endoscopic view of transgastric gallbladder drainage with a LAMS
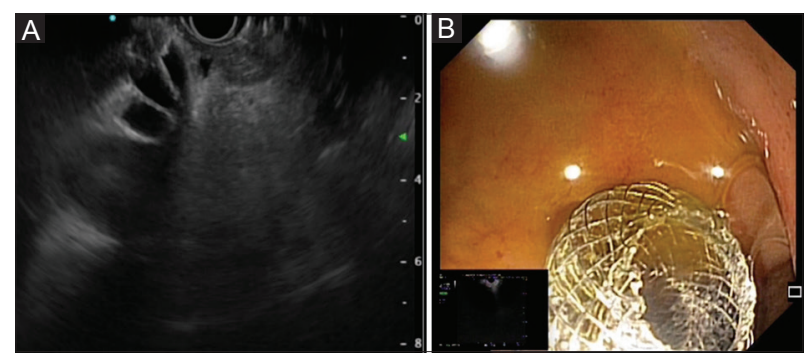

Figure 3 (A) Endoscopic ultrasound-guided choledocoduodenostomy by positioning a lumen-apposing metal stent (LAMS). (B) Endoscopic view of the proximal flange of the LAMS placed across the duodenal bulb

replacing surgical or percutaneous approaches. The introduction of new devices specifically designed for EUSguided drainage, such as LAMS, has enabled other transluminal endoscopic procedures such as biliary and gallbladder drainage. Whether the use of these devices will allow EUSguided drainage procedures to be performed, not only by a few experts, but also by a wider panel of well-trained endoscopists is currently not known.

The electrocautery tip allows the passage of the catheter into the target lumen without prior tract dilation, potentially increasing the feasibility and efficacy of the method and reducing the rate of adverse events. To date, the effectiveness and adverse events of transmural EUS-guided drainage have been described in case series focusing on single clinical indications and mainly using the first type of LAMS, which lacked the electrocautery-enhanced delivery system. In the present study, the use of the LAMS was shown to be feasible, safe and effective in procedures performed by expert endoscopists for the management of different clinical indications requiring transluminal endoscopic interventions (PFCs, gallbladder, and biliary drainage). It is important to underscore that LAMS placement was successfully performed in $98 \%$ of cases, 
Table 2 Patients who underwent endoscopic ultrasound-guided gallbladder drainage with a lumen-apposing metal stent

Characteristics of patients $(\mathrm{N}=10)$

\begin{tabular}{lc}
\hline Sex $[\mathrm{n}(\%)]$ & Male 5 (50\%) \\
\hline Age, $y[$ mean \pm SD] & $79 \pm 10.1$ \\
\hline Successful stent deployment [n (\%)] & $10(100 \%)$ \\
\hline Procedural time, min [mean \pm SD] & $28.1 \pm 12.5$ \\
\hline Access route [n (\%)] & $\begin{array}{c}\text { Transgastric 4 (40\%) } \\
\text { Transduodenal 6 (60\%) }\end{array}$ \\
\hline Stent diameter [n (\%)] & 10 mm $8(80 \%)$ \\
\hline Technical success & 15 mm 2(20\%) \\
Immediate adverse events [n (\%)] & $10(100 \%)$ \\
Late adverse events [n (\%)] & $1(10 \%)$ \\
Clinical success [n (\%)] & $1(10 \%)$ \\
\hline $\begin{array}{l}\text { Follow-up duration after stent } \\
\text { insertion, days [mean } \pm S D]\end{array}$ & $9(90 \%)$ \\
\hline
\end{tabular}

Table 3 Patients who underwent endoscopic ultrasound-guided biliary drainage with a lumen-apposing metal stent

Characteristics of patients $(\mathrm{N}=16)$

\begin{tabular}{|c|c|}
\hline $\operatorname{Sex}[\mathrm{n}(\%)]$ & Male $8(50 \%)$ \\
\hline Age, y $[$ mean \pm SD] & $69.9 \pm 13.3$ \\
\hline Successful stent deployment [n (\%)] & $15(93.8 \%)$ \\
\hline Procedural time, min $[$ mean $\pm S D]$ & $39.4 \pm 22.1$ \\
\hline \multirow[t]{2}{*}{ Access route $[\mathrm{n}(\%)]$} & Transgastric $1(6.2 \%)$ \\
\hline & Transbulbar 15 (93.8\%) \\
\hline \multirow[t]{3}{*}{ Stent diameter $[\mathrm{n}(\%)]$} & $6 \mathrm{~mm} 9(56.2 \%)$ \\
\hline & $8 \mathrm{~mm} 4(25.0 \%)$ \\
\hline & $10 \mathrm{~mm} 3(18.8 \%)$ \\
\hline Technical success & $15(93.8 \%)$ \\
\hline Immediate adverse events [n (\%)] & 0 \\
\hline Late adverse events [n (\%)] & $1(6.6 \%)$ \\
\hline Clinical success [n (\%)] & $14(93.3 \%)$ \\
\hline $\begin{array}{l}\text { Follow-up duration after stent } \\
\text { insertion, days }[\text { mean } \pm S D]\end{array}$ & $138.7 \pm 124.6$ \\
\hline
\end{tabular}

regardless of the indication. In addition to the high rate of technical success, we observed an overall clinical success of $86.4 \%$. Patients who underwent LAMS placement for biliary drainage and gallbladder were more likely to have successful treatment than those with PFCs (93.3\%/90\% vs. $78.6 \%)$. The three patients in the PFC subgroup who did not have a favorable outcome had incomplete resolution of the PFC, even though they experienced significant clinical improvement and remained asymptomatic. In fact, we achieved complete resolution in all other PFC patients without recurrence after stent removal, successfully and easily performed when attempted.

Our results are consistent with other previous studies $[1,15]$ that analyzed the safety and clinical efficacy of the LAMS with cautery system for EUS-guided drainage of PFCs. In these large multicenter studies, which included more cases than our series, technical and clinical success rates were $100 \%$ and $98.9 \%$ for PFCs, and 88.2-92.5\% for WONs. In our PFC patients adverse events were infrequent (11.1\%), with a lower rate than previously reported [16]. However, the earlier study was larger, multicentric and with a higher proportion of complex collections, making any comparison difficult. Moreover, the variability in the technique among endoscopists from different centers could have negatively influenced the occurrence of adverse events.

EUS-guided transmural gallbladder drainage has recently emerged as an alternative to percutaneous cholecystostomy in high-risk patients with acute cholecystitis [3] who also have a prolonged international normalized ratio and/or are on anticoagulation [17]. Walter et al [5], in a multicenter prospective study on the use of LAMS for EUS-guided gallbladder drainage in high-risk surgical patients, reported an overall technical success rate of $90 \%$ and a clinical success rate of $96 \%$. However, serious adverse events were observed in 50\% of patients and the overall mortality was $23 \%$. In the present study, we observed similar technical (100\%) and clinical success $(90 \%)$ rates, but a lower adverse event rate (10\%) and lower procedure-related mortality (10\%).

Only a few studies have evaluated the use of LAMS for EUSguided biliary drainage. Kunda et al [6] described 57 patients who underwent EUS-choledochoduodenostomy for malignant distal biliary obstruction by LAMS, with or without the electrocautery-enhanced delivery system, and reported technical and clinical success rates of $98.2 \%$ and $96.4 \%$, respectively, with a major procedural complication rate of $7 \%$. As reported above, in our series we observed similar technical (93.8\%) and clinical success (93.3\%) rates. Despite the limited data and the preliminary results, a recent meta-analysis [18] comparing EUS-guided biliary drainage and percutaneous transhepatic biliary drainage concluded that EUS procedure should be preferred because of its higher clinical success and lower complication and reintervention rates. Concerns about the safety and efficacy of specifically designed devices for transmural EUS-guided drainage such as LAMS have recently been raised in the literature [19].

The LAMS has been demonstrated to have a higher success rate for drainage of WONs. The shape of the LAMS enables direct endoscopic debridement by passage of the standard endoscope through the stent lumen, and the anchoring flanges prevent stent dislodgment during endoscopic necrosectomy. Despite these advantages, data from recent studies do not provide evidence of significant superiority of LAMS over fully covered self-expanding metal stents (FCSEMS). Currently, the largest study evaluating the use of different types of FCSEMs for the endoscopic treatment of PFCs comes from Spain. In their retrospective review of a nationwide database, VasquezSequeiros et al [20] reported overall technical success and 
a sustained clinical improvement in $97 \%$ and $85 \%$ of cases, respectively. The authors found LAMS and straight biliary FCSEMS to be equally effective and safe. However, in this study most of the FCSEMS employed were straight biliary (70\%) and the LAMS were not incorporated in the electrocauteryenhanced delivery system used in our study.

When efficacy and outcome are similar, the selection of the type of stent to employ for EUS-guided drainage must take costs into account. Although at present LAMS are more expensive than FCSEMS, the shorter procedure time and the probable greater efficacy in specific situations, such as WON, could potentially outweigh the economic issue. This issue is still under debate. Guo et al [21], in a multi-institutional consensus on how to perform EUS-guided peri-PFC drainage and endoscopic necrosectomy, suggested that LAMS should be the standard of care for the creation of an endoscopic cystenterostomy in WON. On the other hand, in a recent randomized trial [22] that compared LAMS with a plastic stent for WON treatment, serious adverse events were observed in the LAMS group; the authors concluded that LAMS removal should be performed at 3 weeks, if the WON has resolved, to decrease complications. Moreover, except for procedure duration, there was no significant difference in treatment outcomes between LAMS and plastic stents. Hence, the first current guidelines on interventional EUS procedures published by an endoscopic society [23] stated that the use of metallic stents for pancreatic pseudocyst drainage outside a clinical trial is not recommended, with a moderate level of evidence.

There are several limitations to our study. Being a retrospective study, it had intrinsic limitations such as variable follow up of patients. Our series was also limited by the small size of the study population and the lack of a comparison group. The strengths of the present study are the single technique used by the endoscopists and the availability of accurate follow-up data for the majority of patients.

In conclusion, the use of LAMS specifically designed for EUS-guided drainage, such as Hot AXIOS, holds promise as an alternative procedure to surgery and percutaneous radiological drainage in other clinical situations apart from PFCs, such as gallbladder and biliary drainage, when performed by expert endoscopists in tertiary level centers. The better technical and clinical success and the lower frequency of major complications associated with the use of the new delivery system with an electrocautery tip, as evidenced by our series, must be confirmed by multicenter controlled studies in larger populations, including cost-effectiveness analysis. Moreover, appropriate clinical selection and standardization of the technique are warranted in order to minimize adverse events.

\section{References}

1. Siddiqui AA, Adler DG, Nieto J, et al. EUS-guided drainage of peripancreatic fluid collections and necrosis by using a novel lumen-apposing stent: a large retrospective, multicenter U.S. experience (with videos). Gastrointest Endosc 2016;83:699-707.

2. Irani S, Ngamruengphong S, Teoh A, et al. Similar efficacies of endoscopic ultrasound gallbladder drainage with a lumen-apposing metal stent vs percutaneous transhepatic gallbladder drainage for acute cholecystitis. Clin Gastroenterol Hepatol 2017;15:738-745.

3. Anderloni A, Buda A, Vieceli F, Khashab MA, Hassan C, Repici A. Endoscopic ultrasound-guided transmural stenting for gallbladder drainage in high-risk patients with acute cholecystitis: a systematic review and pooled analysis. Surg Endosc 2016;30:5200-5208.

4. Kunda R, Pérez-Miranda M, Will U, et al. EUS-guided choledochoduodenostomy for malignant distal biliary obstruction using a lumen-apposing fully covered metal stent after failed ERCP. Surg Endosc 2016;30:5002-5008.

5. Walter D, Teoh AY, Itoi T, et al. EUS-guided gall bladder drainage with a lumen-apposing metal stent: a prospective long-term evaluation. Gut 2016;65:6-8.

6. Walter D, Will U, Sanchez-Yague A, et al. A novel lumen-apposing metal stent for endoscopic ultrasound-guided drainage of pancreatic fluid collections: a prospective cohort study. Endoscopy 2015;47:63-67.

7. Veitch AM, Vanbiervliet G, Gershlick AH, et al. Endoscopy in patients on antiplatelet or anticoagulant therapy, including direct oral anticoagulants: British Society of Gastroenterology (BSG) and European Society of Gastrointestinal Endoscopy (ESGE) guidelines. Gut 2016;65:374-389.

8. Muthusamy VR, Chandrasekhara V, Acosta RD, et al; ASGE Standards of Practice Committee. The role of endoscopy in the diagnosis and treatment of inflammatory pancreatic fluid collections. Gastrointest Endosc 2016;83:481-488.

9. Pezzilli R, Zerbi A, Campra D, et al; Italian Association for the Study of the Pancreas (AISP). Consensus guidelines on severe acute pancreatitis. Dig Liver Dis 2015;47:532-543.

10. Dollhopf M, Larghi A, Will U, et al. EUS-guided gallbladder drainage in patients with acute cholecystitis and high surgical risk using an electrocautery-enhanced lumen-apposing metal stent device. Gastrointest Endosc 2017;86:636-643.

11. Yokoe M, Takada T, Strasberg SM, et al; Tokyo Guidelines Revision

\section{Summary Box}

\section{What is already known:}

- Endoscopic ultrasound (EUS) is used to achieve drainage of pancreatic fluid collections, and of the gallbladder and biliary tract

- New devices specifically designed for interventional EUS, such as the lumen-apposing metal stent (LAMS) with cautery system, have simplified the procedure

- The study aimed to assess the effectiveness and safety of this approach

\section{What the new findings are:}

- EUS-guided placement of the LAMS with cautery system has high technical and clinical success rates in all the three clinical settings

- The procedure has a good risk profile in all indications

- The technique is a time-saving procedure, a very important feature in critically ill patients 
Committee. TG13 diagnostic criteria and severity grading of acute cholecystitis (with videos). J Hepatobiliary Pancreat Sci 2013;20:35-46.

12. Anderloni A, Attili F, Carrara S, et al. Intra-channel stent release technique for fluoroless endoscopic ultrasound-guided lumenapposing metal stent placement: changing the paradigm. Endosc Int Open 2017;5:E25-E29.

13. Chandran S, Efthymiou M, Kaffes A, et al. Management of pancreatic collections with a novel endoscopically placed fully covered self-expandable metal stent: a national experience (with videos). Gastrointest Endosc 2015;81:127-135.

14. Anderloni A, Buda A, Carrara S, et al. Single-session doublestent placement in concomitant malignant biliary and duodenal obstruction with a cautery-tipped lumen apposing metal stent. Endoscopy 2016;48:E321-E322.

15. Rinninella E, Kunda R, Dollhopf M, et al. EUS-guided drainage of pancreatic fluid collections using a novel lumen-apposing metal stent on an electrocautery-enhanced delivery system: a large retrospective study (with video). Gastrointest Endosc 2015;82:1039-1046.

16. Patil R, Ona MA, Papafragkakis C, Anand S, Duddempudi S. Endoscopic ultrasound-guided placement of AXIOS stent for drainage of pancreatic fluid collections. Ann Gastroenterol 2016;29:168-173.

17. Anderloni A, Attili F, Sferrazza A, et al. EUS-guided gallbladder drainage using a lumen-apposing self-expandable metal stent in patients with coagulopathy or anticoagulation therapy: a case series. Endosc Int Open 2017;5:E1100-E1103.

18. Sharaiha RZ, Tyberg A, Khashab MA, et al. Endoscopic therapy with lumen-apposing metal stents is safe and effective for patients with pancreatic walled-off necrosis. Clin Gastroenterol Hepatol 2016;14:1797-1803.

19. Voermans RP, Fockens P. Endoscopic transluminal drainage of walled-off necrosis: Does size matter? Gastrointest Endosc 2016;83:708-710.

20. Vazquez-Sequeiros E, Baron TH, Pérez-Miranda M, et al; Spanish Group for FCSEMS in Pancreas Collections. Evaluation of the short- and long-term effectiveness and safety of fully covered selfexpandable metal stents for drainage of pancreatic fluid collections: results of a Spanish nationwide registry. Gastrointest Endosc 2016;84:450-457.

21. Guo J, Saftoiu A, Vilmann P, et al. A multi-institutional consensus on how to perform endoscopic ultrasound-guided peri-pancreatic fluid collection drainage and endoscopic necrosectomy. Endosc Ultrasound 2017;6:285-291.

22. Bang JY, Navaneethan U, Hasan MK, Sutton B, Hawes R, Varadarajulu S. Non-superiority of lumen-apposing metal stents over plastic stents for drainage of walled-off necrosis in a randomised trial. Gut 2018 Jun 1 [Epub ahead of print]. doi: 10.1136/gutjnl-2017-315335.

23. Teoh AYB, Dhir V, Kida M, et al. Consensus guidelines on the optimal management in interventional EUS procedures: results from the Asian EUS group RAND/UCLA expert panel. Gut 2018;67:1209-1228. 